\title{
AC 2008-521: EFFECTS OF ACTIVE LEARNING ON STUDENT PERFORMANCE AND RETENTION
}

\section{Lisa Bullard, North Carolina State University}

Lisa G. Bullard is a Teaching Associate Professor and the Director of Undergraduate Studies in the Department of Chemical and Biomolecular Engineering at North Carolina State University. She received her BS in ChE from NC State and her Ph.D. in ChE from Carnegie Mellon, and she served in engineering and management positions within Eastman Chemical Co. from 1991-2000.

\section{Richard Felder, North Carolina State University}

Richard M. Felder is the Hoechst Celanese Professor Emeritus of Chemical Engineering at North Carolina State University. He received his BS in ChE from the City College of New York and his $\mathrm{Ph}$.D. in $\mathrm{ChE}$ from Princeton. He is coauthor of Elementary Principles of Chemical Processes and numerous articles in science and engineering education and chemical process engineering, and he co-directs the ASEE National Effective Teaching Institute (NETI).

\section{Dianne Raubenheimer, North Carolina State University}

C. Dianne Raubenheimer is the Director of Assessment in the College of Engineering at NCSU. She received BSc, MSc and MEd degrees from the University of Natal, South Africa and a PhD from the University of Louisville, Kentucky. Her background is in science teacher preparation, curriculum development and evaluation. She teaches as an adjunct in the department of Adult and Higher Education at NCSU. 


\title{
EFFECTS OF ACTIVE LEARNING ON STUDENT PERFORMANCE AND RETENTION IN CHEMICAL ENGINEERING
}

\begin{abstract}
During a five-year period from 2002 through 2006, parallel sections of the introductory sophomore chemical engineering course ("Chemical Process Principles") were taught by different instructors in the same or adjacent time slots, so that both sections could be given the same midterm examinations. It usually happened that one section was taught in a traditional lecture-based format and the other was taught using extensive active learning, with group activities in every class session. The mode of instruction made relatively little difference to students with high first-year grade-point averages, but low-GPA students in the active classes consistently outperformed traditionally-taught low-GPA students on common exams and homework assignments and were also more likely to drop out of chemical engineering after the course. This paper summarizes the results and discusses their implications for instruction in engineering gateway courses.
\end{abstract}

\section{Introduction}

High rates of student attrition have been a source of concern among engineering educators for many decades. Efforts to reduce attrition have focused primarily on the first year of the engineering curriculum, with various measures being taken to improve instruction in the basic science and mathematics courses and to make the freshman engineering course a more instructive and exciting experience than it has traditionally been. Another serious source of attrition is the first course in the engineering major-the statics course in civil and mechanical engineering, the circuits course in electrical engineering, and the stoichiometry (material and energy balances) course in chemical engineering. Failure rates of 50\% and higher are not uncommon, and many students who drop out of engineering do so as a consequence of their experiences in these courses.

This is not to say that the goal should be to eliminate attrition from engineering curricula. Many students who matriculate in engineering do so because of the promise of high starting salaries or family pressures or simply having done well in high school science and math, and not because of a particular interest in or aptitude for engineering. Not everyone would be happy in an engineering career, and the best thing that could happen to some students is to drop out of engineering and switch to a curriculum that would lead to more enjoyable and fulfilling careers. The goal for the first engineering course should be to provide a realistic and well-taught introduction to the discipline, so that all students with the ability and interest needed to do well as engineers have an experience that motivates them to remain in engineering.

Most chemical engineering curricula begin with a second-year course on material and energy balances on chemical processes, historically designated the "stoichiometry course." The course is generally feared by students, with their descriptions of it invariably including the term "weed-out." Test grades tend to be low, failure rates are high, and student course ratings are 
routinely the lowest of any course in the curriculum. Most students who drop out of chemical engineering probably do so as a consequence of their experience in the stoichiometry course, either because they failed it or they simply disliked it. Beginning in the late 1970s, a new student-centered approach to teaching the stoichiometry course at N.C. State University (CHE 205) was adopted by some but not all chemical engineering faculty. Initially, the defining characteristic of the approach was active learning, meaning that most or all lectures included several brief activities that provide practice and feedback in the problem-solving methods required on homework and tests. ${ }^{2,3}$ This approach has been augmented in recent years by an extensive coursepack containing the basic lecture notes with blank spaces where students fill in answers to questions, missing equations or terms of equations, and partial solutions to problems that they may work on individually or in groups. Subsequently, the approach was expanded to include cooperative learning (some homework assignments solved by student teams, with measures taken to hold individual team members accountable for the solutions to all problems) and inductive (inquiry-based) learning. Specific examples of how these methods were implemented are given in Reference 1.

The student-centered approach just described was not implemented as an experiment to see if active, cooperative, and inductive learning work, or to determine whether they work in an engineering class. Hundreds of such experiments have already been carried out, and the overwhelming body of evidence attests to the superiority of those methods over traditional teacher-centered instruction in which course content is delivered exclusively in lectures and students only work individually on homework problems. ${ }^{4-7}$ Rather, the approach was adopted out of the instructors' research-based conviction that it was simply the most effective way to teach the course.

Throughout the past decade, the fall offering of the stoichiometry course has been given in two sections, with each section containing anywhere from 40 to 90 students. It often happened that the two sections were taught by different instructors, one of whom used active learning and the other a traditional lecture-based approach but in other respects taught identically (same syllabus, learning objectives, and homework assignments). During the time period of this study, three instructors taught the course using the traditional approach and two instructors taught it using the active approach. For reasons of both fairness and convenience, a two-hour time slot was designated on Friday afternoon during which students in both sections took common midterm examinations that were constructed jointly by the two course instructors. Over the years the instructors of the active sections (two of the authors of this paper) noticed that the average test scores in their sections were consistently higher than the averages for the sections taught traditionally, which led to a decision to see if the differences were statistically significant. The thought then occurred that since the stoichiometry course establishes the foundation and sets the tone for the entire chemical engineering curriculum, the nature of the course instruction might affect students' subsequent decisions to stay in the curriculum or transfer out. The data required to test the hypotheses that active learning improved both student test performance and retention in chemical engineering were gathered and analyzed. This paper outlines the study and summarizes the results.

\section{Instruction in the Stoichiometry Course}


CHE 205 is normally taken by students majoring in chemical engineering in the first semester of the second year of the curriculum. Prerequisites for it include a semester each of calculus, physics, and chemistry. The course covers Chapters 1-9 of Elementary Principles of Chemical Processes. ${ }^{8}$ The text is supplemented with a coursepack containing handouts for each chapter with interspersed questions and problems and blank spaces for answers and solutions. The syllabus, course policies, assignment schedule, handouts, study guides, sample tests, and other course materials may be viewed at

\section{$<$ <ttp://www.ncsu.edu/felder-public/cbe205site/cbe205.html>}

If the handouts were used at all in the traditional sections, they were either recommended to the students as supplementary readings or treated as straight lecture notes, while in the active sections the classes consisted of alternating mini-lectures and activities that focused on the handouts. The students would individually read a passage of text or part of a problem statement or solution in a handout and perhaps briefly discuss it in small groups to make sure they understood it. When they reached a gap, one of several different things might happen: (a) the instructor might go through the solution at the board in traditional lecture format; (b) the students might be given a short time (30 seconds-3 minutes) to try to fill in the gap; or (c) the instructor might skip the gap and tell the students to be sure they knew what went in it before they got to the next exam. The class was told and periodically reminded that some of the questions and problem segments in the handouts would show up on the exams, and they did. Activities were sometimes done by pairs or groups of three and sometimes by individuals, alternating among the formats for active learning outlined in Reference 3.

\section{Common Midterm Examination Grades}

We collected data on common CHE 205 midterm examination grades for the fall semesters of 2002-2006. The numbers of students in the active and traditional sections are shown in Table 1.

Table 1. Total Enrollments in the Active and Traditional Sections.

\begin{tabular}{|c|c|c|}
\hline & A & T \\
\hline $\mathbf{2 0 0 2}$ & 47 & 64 \\
\hline $\mathbf{2 0 0 3}$ & 67 & 25 \\
\hline $\mathbf{2 0 0 4}$ & 69 & 31 \\
\hline \multirow{2}{*}{$2005 *$} & 53 & - \\
& 57 & - \\
\hline $\mathbf{2 0 0 6}$ & 70 & 38 \\
\hline
\end{tabular}

* Both sections were active in 2005

In our initial comparisons between grades in the active and traditional sections, most of the between-section differences were found to be highly significant. We then noticed that a disproportionate number of students with high first-year grade-point averages (GPAs) had enrolled in the active sections, so that direct comparisons between the two groups were biased in favor of the actively-taught students. We are not sure why this imbalance occurred, but we would speculate that since honors and scholarship students get priority in registration and the usual 
instructor of the active sections is the coordinator of advising for the Chemical and Biomolecular Engineering Department, many or most of the high-GPA students might have chosen to go with someone they already knew, filling her section and forcing more of the lower-GPA students to enroll in the traditionally-taught section. In addition, while student evaluations are not published at N.C. State University, the student grapevine is very efficient, and the active course instruction and instructors have consistently received higher end-of-course student ratings, which could have led students with registration priority to gravitate to those sections.

We next reasoned that excellent students are relatively likely to master course material regardless of the instructional approach used in the course, and if there are a lot of students with high first-year GPAs in the class (which there were), the chances of finding significant betweensection differences in test grades when GPA is controlled for would be relatively low. Weaker students stand to gain the greatest benefit from pedagogically superior instruction, since they have the greatest room for improvement. We accordingly stratified the student data by first-year GPA and compared grades on common tests and homework assignments earned by students in each section with first-year GPAs of $(a) 3.5$ to 3.15 and $(b)$ less than 3.15 , verifying in each case that there was no significant difference between the active and traditional groups in average firstyear GPA. These data were averaged over all five years of the study, and two-sample one-sided t-tests assuming unequal variances were carried out to test the hypothesis that the average grades for the active sections (including both sections taught in 2005) were greater than those for the traditional sections. The results for the two GPA strata are shown in Table 2.

Table 2. Comparisons of Grades on Common Tests and Homework Assignments

\begin{tabular}{|c|c|c|c|c|c|c|c|c|}
\hline & \multicolumn{2}{|c|}{ Test 1} & \multicolumn{2}{|c|}{ Test 2} & \multicolumn{2}{|c|}{ Test 3} & \multicolumn{2}{|c|}{ HW } \\
\hline \multicolumn{9}{|c|}{ GPA $=3.5$ to 3.15} \\
\hline Group $^{a}$ & A* & $\mathbf{T *}$ & $\mathbf{A}$ & $\mathbf{T}$ & $\mathbf{A}$ & $\mathbf{T}$ & $\mathbf{A}$ & $\mathbf{T}$ \\
\hline $\mathbf{N}^{*}$ & 69 & 33 & 69 & 32 & 68 & 30 & 70 & 34 \\
\hline Mean & 76 & 70 & 68 & 67 & 75 & 80 & 80 & 71 \\
\hline SD & 15 & 22 & 16 & 21 & 20 & 17 & 16 & 20 \\
\hline A-T & \multicolumn{2}{|c|}{5.8} & \multicolumn{2}{|c|}{1.1} & \multicolumn{2}{|c|}{0.27} & \multicolumn{2}{|c|}{9.2} \\
\hline $\mathbf{p}$ & \multicolumn{2}{|c|}{0.18} & \multicolumn{2}{|c|}{0.79} & \multicolumn{2}{|c|}{0.34} & \multicolumn{2}{|c|}{0.02} \\
\hline \multicolumn{9}{|c|}{ GPA $<3.15$} \\
\hline Group $^{b}$ & $\mathbf{A}$ & $\mathbf{T}$ & $\mathbf{A}$ & $\mathbf{T}$ & $\mathbf{A}$ & $\mathbf{T}$ & $\mathbf{A}$ & $\mathbf{T}$ \\
\hline $\mathbf{N}$ & 97 & 54 & 96 & 49 & 93 & 49 & 97 & 57 \\
\hline Mean & 73 & 70 & 64 & 64 & 74 & 67 & 76 & 57 \\
\hline SD & 14 & 20 & 19 & 18 & 15 & 18 & 17 & 28 \\
\hline A-T & \multicolumn{2}{|c|}{2.3} & \multicolumn{2}{|c|}{-0.5} & \multicolumn{2}{|c|}{6.8} & \multicolumn{2}{|c|}{19.2} \\
\hline $\mathbf{p}$ & \multicolumn{2}{|c|}{0.46} & \multicolumn{2}{|c|}{0.87} & \multicolumn{2}{|c|}{0.03} & \multicolumn{2}{|c|}{$<0.0001$} \\
\hline
\end{tabular}


The average first-year GPAs, shown at the bottom of Table 2, were slightly higher for the active group than for the traditional group for both GPA strata, but not significantly so. The average test score for the active group was slightly higher than that for the traditional group on Test 1 and essentially the same on Test 2 . In the high-GPA group the traditionally-taught students earned a higher (but not significantly higher) average score on Test 3 than the actively taught students did, and the opposite result was observed for the low-GPA group, with the difference being statistically significant. The average homework grades were significantly higher for the active sections than for the traditional sections in both GPA strata. For the actively-taught students, the grades received by the high- and low-GPA groups on each test and the homework were fairly close, but on the third test and the homework the traditionally-taught students in the high-GPA group did noticeably better than their low-GPA counterparts.

The data do not support a general hypothesis that active learning leads to an improvement in student performance in the introductory chemical engineering course comparable to the improvements that have been found in many other courses studied. ${ }^{5}$ They suggest, however, that significant performance improvements are likely to be observed for the academically weaker students in the class who are at greatest risk for failing or dropping out.

\section{Retention in Chemical Engineering}

We believe that having a positive educational experience in the introductory course in a curriculum should tend to strengthen a student's resolve to remain in that curriculum. We accordingly hypothesized that being taught CHE 205 actively would reduce students' likelihood of dropping out of chemical engineering.

To test this hypothesis, we collected enrollment status data for all of the students in our sample populations who entered the university as freshmen and who were either matriculated or intended to matriculate in chemical engineering at the time they took CHE 205 (which eliminated students in other curricula that require CHE 205), and determined how many of them were still enrolled in Chemical Engineering one year and two years after they began the course. Transfer students, even if they were Chemical Engineering majors, were not included in this analysis because of the impossibility of determining a meaningful first-year GPA for them. We used a one-sided Fisher's exact test (a nonparametric test of categorical data frequency differences) to determine the statistical significance of the differences in retention between the active and traditional groups. The results for both GPA strata are shown in Table 3.

Table 3. Percentage Retentions of Students in CBE stratified by GPA

\begin{tabular}{|l|c|c|c|c|c|c|}
\hline \multicolumn{7}{|c|}{ GPA = 3.5 to 3.15 } \\
\hline & Start Year 2 & \multicolumn{2}{|c|}{ Start Year 3 } & \multicolumn{2}{|c|}{ Start Year 4 } \\
\hline & N & GPA & N & \% ret. & N & \% ret. \\
\hline (a) Active & 29 & 3.34 & 25 & $86 \%$ & 22 & $76 \%$ \\
\hline (b) Traditional & 10 & 3.31 & 9 & $90 \%$ & 8 & $80 \%$ \\
\hline$p_{(a)-(b) \text { Fisher's exact test }}$ GPA < 3.15 \\
\hline \multicolumn{8}{|c|}{ Start Year 2 } & Start Year 3 & Start Year 4 \\
\hline
\end{tabular}




\begin{tabular}{|l|c|c|c|c|c|c|}
\hline & N & GPA & N & \% ret. & N & \% ret. \\
\hline (a) Active & 28 & 2.82 & 20 & $71 \%$ & 17 & $61 \%$ \\
\hline (b) Traditional & 10 & 2.72 & 5 & $50 \%$ & 2 & $20 \%$ \\
\hline $\boldsymbol{p}_{(a)-(b) \text { Fisher's exact test }}$ & \multicolumn{3}{|c|}{0.2} & \multicolumn{2}{|c|}{0.03} \\
\hline
\end{tabular}

There was essentially no difference in retention between students in the high-GPA stratum taught actively and traditionally; however, for students with first-year GPAs less than 3.15, the retention of the active group was dramatically higher at the start of both Year 3 and Year 4, with the difference at the start of Year 4 reaching statistical significance. The average GPAs for the active and traditional groups in that strata were 2.82 and 2.72, respectively, a non-significant difference that is almost certainly not large enough to explain the differences in retention between the two groups. The data support a claim that low-GPA students in the active sections were significantly more likely to persist in the chemical engineering curriculum than were low-GPA students in the traditional sections.

\section{Summary and Conclusions}

The introductory chemical engineering course was taught to two parallel sections of students in each year from 2002 through 2006. In all but one of those years, one section was taught using extensive active learning, and the other was taught in a traditional lecture-based manner. Common midterm examinations and homework assignments were given to both sections. The students were stratified into two groups according to their first-year grade-point averages, with one stratum consisting of students with GPA between 3.15 and 3.5 and the other with GPA less than 3.15. (We did not study students with GPA>3.5, reasoning that the best students would be likely to do well regardless of how the course was taught.) The average grades on the midterms and assignments earned by the students taught actively and by those taught traditionally were compared for each GPA group, as were retentions in chemical engineering of students taught actively and traditionally.

Comparisons of performance on common assessments did not show consistently significant differences, although on one of the tests the actively-taught students in the low-GPA stratum scored significantly higher than the traditionally-taught students and the actively-taught students in both strata earned significantly higher homework grades than their traditionallytaught counterparts. For students in the high-GPA stratum there was very little difference in curricular retention between students taught actively and traditionally, but in the low-GPA stratum the actively-taught students were far more likely to remain in chemical engineering, with the difference after two years being statistically significant. The trends favoring the activelytaught sections were observed even though the active class sections were from 1.3 to 2.7 times larger, which would be expected to work to the advantage of the traditionally-taught classes. While more study is needed to firmly establish the quantitative effects of active learning in the introductory chemical engineering course, the results provide strong motivation for critical examination of the pedagogy in gateway courses, particularly with regard to its impact on student performance and retention. 


\section{References}

1. L.G. Bullard and R.M. Felder, "A Student-Centered Approach to Teaching Material and Energy Balances. 1. Course Design." Chem. Engr. Education, 41(2), 93-100 (2007), <http://www.ncsu.edu/felder-

public/Papers/StoichPap-pt1.pdf>; 2. Course Instruction and Assessment." Chem. Engr. Education, 41(3), 167176 (2007), <http://www.ncsu.edu/felder-public/Papers/StoichPap-pt2.pdf>.

2. Felder, R.M., "Stoichiometry without Tears," Chem. Engr. Education, 24(4), 188 (1990).

$<$ http://www.ncsu.edu/felder-public/Papers/StoichiometryWithoutTears.pdf $>$.

3. Felder, R.M. and R. Brent, "Learning by Doing," Chem. Engr. Education, 37(4), 282-283 (2003), $<$ http://www.ncsu.edu/felder-public/Columns/Active.pdfs.

4. Felder, R.M., G.N. Felder, and E.J. Dietz, "A Longitudinal Study of Engineering Student Performance and Retention. V. Comparisons with Traditionally-Taught Students," J. Engr. Education, 87(4), 469-480 (1998). $<$ http://www.ncsu.edu/felder-public/Papers/long5.html>.

5. Prince, M., "Does Active Learning Work? A Review of the Research," J. Engr. Education, 93(3), 223-231 (2004). <http://www.ncsu.edu/felder-public/Papers/Prince_AL.pdfs.

6. Prince, M.J., and R.M. Felder, "Inductive Teaching and Learning Methods: Definitions, Comparisons, and Research Bases," J. Engr. Education, 95(2), 123-138 (2006). <http://www.ncsu.edu/felderpublic/Papers/InductiveTeaching.pdf>.

7. Smith, K.A., S.D. Sheppard, D.W. Johnson, and R.T. Johnson, "Pedagogies of Engagement: Classroom-Based Practices," J. Engr. Education, 94(1), 87-101 (2005).

8. Felder, R.M. and R.W. Rousseau, Elementary Principles of Chemical Processes, 2005 Upgrade Edition, New York: John Wiley \& Sons, 2005. 